\title{
THE EVALUATION AND TREATMENT OF GASTROINTESTINAL DISEASE IN CHILDREN WITH CYSTINOSIS RECEIVING CYSTEAMINE
}

\author{
RANJAN DOHIL, MBBCh, MRCP, ROBERT O. NeWBuRy, MD, ZaChary M. SelLeRs, BSC, \\ ReENA Deutsch, PhD, AND JeRry A. SCHNEIDER, MD
}

Objectives Cysteamine prevents organ damage in children with eystinosis, but may cause gastrointestinal (GI) symptoms. In this study we evaluated the nature of GI disease, and the value of omeprazole in controlling GI symptoms in these children.

Study design Upper GI disease was evaluated with endoscopy, gastrin levels, and acid secretion studies after oral administration of cysteamine, before and after 16 weeks of therapy with omeprazole. A symptom score was devised.

Results Eleven children (mean age, 5.7 years) were studied. After cysteamine ingestion, before and after omeprazole therapy, the mean maximum acid output was significantly higher than the mean basal acid output. The maximum acid output was measured within 60 minutes of cysteamine ingestion and was reduced by omeprazole therapy $(P<.01)$. The mean peak gastrin level was 30 minutes postcysteamine and was higher than baseline $(P<.01)$. The initial mean symptom score $(m a x i m u m$ score, 14) was 6.9 and fell to $0.7(P<.0001)$ after 16 weeks of omeprazole therapy. At endoscopy, two children had diffuse gastric nodularity, and nearly all had cystine crystal deposits.

Conclusions GI symptoms in children with cystinosis receiving cysteamine are often acid-mediated and improve with omeprazole. Cystine crystals were detected in the GI tract and may signify inadequate treatment with cysteamine. ( $J$ Pediatr 2003;143:224-30)

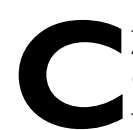

ystinosis is an autosomal recessive disease caused by the abnormal accumulation of cystine within various tissues. ${ }^{1}$ The nephropathic forms of cystinosis are associated with multi-organ damage, particularly progressive renal failure leading to dialysis and/or renal transplantation. To date, the only specific treatment for nephropathic cystinosis is the sulfhydryl agent, cysteamine; this drug lowers intracellular cystine levels, thereby reducing the rate of progression of renal failure ${ }^{2,3}$ and significantly diminishing damage to other organs. ${ }^{1}$

Cysteamine is known to be ulcerogenic in laboratory animals and has been used specifically for this purpose. ${ }^{4,5,6}$ The mechanism of cysteamine-induced ulcerogenesis is most likely multifactorial and may involve increased gastrin and gastric acid production, ${ }^{5-7}$ delayed gastric emptying, and inhibition of bicarbonate and gastric mucus production., ${ }^{8,9}$ Oral cysteamine administered to four children with cystinosis caused a mean three-fold increase in gastric acid production above baseline. ${ }^{10} \mathrm{It}$ is therefore not surprising that many children receiving cysteamine therapy have gastrointestinal (GI) symptoms. GI symptoms were found to occur in $93 \%$ of patients with cystinosis. ${ }^{11}$ In a feasibility study where 66 families were interviewed by telephone, almost all children with cystinosis described GI symptoms which included swallowing dysfunction, anorexia, nausea, vomiting, retching, abdominal pain, and heartburn. These symptoms may have contributed to school absenteeism, suboptimal nutrition and growth, and reduced compliance for cysteamine therapy. If indeed cysteamine-associated GI symptoms are caused by increased gastric acid production, then acid-suppression should result in symptom relief, better compliance, and improved prognosis for the patient.

\begin{tabular}{llll}
\hline BAO & Basal acid output & PAO & Peak acid output \\
GI & Gastrointestinal & UCSD & University of California at San Diego \\
MAO & Maximum acid output & & \\
\hline
\end{tabular}

From the Departments of Pediatrics, Medicine, and Family and Preventive Medicine, University of California, San Diego, La Jolla, and the Department of Pathology, Children's Hospital and Health Center, San Diego, California. Supported by National Institute of Health Grant MOIRR00827, and AstraZeneca.

Submitted for publication Sept I I, 2002; revision received Dec 12, 2002, Feb 26, 2003; and accepted May 7, 2003.

Reprint requests: Ranjan Dohil, MBBCh, MRCP, UCSD Medical Center, Hillcrest, 200 West Arbor Dr, San Diego, CA 92103-8450. E-mail: rdohil@ucsd.edu.

Copyright (C) 2003, Mosby, Inc. All rights reserved.

0022-3476/2003/\$30.00+0

10. 1067/S0022-3476(03)0028 I-6 
The purpose of this study was to evaluate the nature and cause of GI disease, and assess the value of the proton-pump inhibitor omeprazole (Prilosec, AstraZeneca, Wilmington, Del) in controlling upper GI symptoms and gastric acid output in children with cystinosis receiving cysteamine therapy. ${ }^{12}$

\section{METHODS}

Recruited patients were admitted to the University of California at San Diego (UCSD) General Clinical Research Center for baseline and then follow-up evaluation after 16 weeks of omeprazole therapy. The study was approved by the University of California at San Diego, Human Subjects Committee, and informed consent was obtained for each participant.

\section{Patients}

Cystinosis patients, ages 1 to 18 years, with GI symptoms were asked to participate in this study. All patients received regular cysteamine bitartrate (Cystagon, Mylan, Morgantown, WV) at a free-base dose of approximately 60 $\mathrm{mg} / \mathrm{kg} /$ day. Acid suppressants, antibiotics, nonsteroidal antiinflammatory drugs, prokinetic agents, and antihistamines were discontinued one month before admission. A mean leukocyte cystine level of $<2.0 \mathrm{nmol}$ half-cystine per mg protein over the past year was required for inclusion in the study.

\section{Serum Gastrin}

After subjects underwent an eight-hour overnight fast, except for water, 3-mL blood samples were taken at baseline and at 30,60, 90, and 120 minutes after ingestion of the patient's regular dose of cysteamine. The cysteamine was administered in solution with water. Serum gastrin levels were measured in $\mathrm{pg} / \mathrm{mL}$ using the Diagnostic Products Corporation (Los Angeles, Calif) gastrin ${ }^{125}$ radioimmunoassay kit. ${ }^{13}$

\section{Gastric Acid Secretion}

On the second study day, and after an overnight fast for everything except water, a multiport 8 French nasogastric tube was inserted into children who did not have a pre-existing gastrostomy tube. To assure correct tube placement, $50 \mathrm{~mL}$ of water was instilled into the stomach, aspirated, and discarded with the overnight gastric contents. The hydrogen ion content within aspirated gastric contents was measured to provide basal acid output (BAO)/maximum acid output (MAO)/peak acid output (PAO) levels. The BAO was estimated from gastric contents collected over 60 minutes in four 15 -minute aliquots. The patient's regular dose of cysteamine was then administered, the feeding tube was clamped for 30 minutes, and the gastric contents were again collected and discarded. Over the next two hours, gastric contents were collected in eight consecutive 15minute aliquots. The MAO was the acid content in the first 60 minutes. The PAO was the highest two consecutive 15 -minute collection periods multiplied by a factor of two to express acid secretion in the usual way, ie, $\mu \mathrm{Eq} / \mathrm{kg} / \mathrm{hr}$. Gastric acid was measured by standard titration method ${ }^{14}$ by using a digital $\mathrm{pH}$ meter (PHM 82 Radiometer, Copenhagen, Denmark).

\section{Upper GI Endoscopy and Biopsies}

This was performed under general anesthesia using an Olympus GIF 100 or P140 endoscope (Olympus, Melville, NY) and through-the-scope biopsy forceps. Mucosal biopsies were fixed in formalin and Trump's solution and sent for hematoxylin and eosin staining and electron microscopy, respectively. Biopsy specimens were examined for inflammation and intracellular cystine deposition. Endoscopic findings were reported in a conventional manner. ${ }^{15,16}$

\section{Symptom Score}

A symptom score was devised to assess GI symptoms at baseline, and at 4, 8, 12, and 16 weeks after commencing omeprazole. Data was obtained either in person or by telephone communication with the physician. Each of the seven symptom categories scored 0 to 2 points depending on the presence and severity of each symptom. Zero points were awarded if the symptom was absent; 1 point if the symptom was mild, did not interfere with daily activities and only required occasional treatment (eg, with oral antacids); and 2 points if the symptoms were severe enough to interrupt daily activities or require regular treatment (eg, with $\mathrm{H}_{2}$-blockers). Previous GI bleeding was considered mild (1 point) if there was no associated hemodynamic compromise or anemia, and severe ( 2 points) if bleeds were multiple, caused anemia, or required blood transfusion. The symptom categories included: (1) heartburn or regurgitation; (2) abdominal pain or unexplained regular irritability in small children; (3) nausea or vomiting; (4) anorexia or early satiety; (5) dysphagia or odynophagia; (6) nocturnal wakening with symptoms; and (7) gastrointestinal bleeding within the four months. The symptom score was the sum of each individual symptom category score. The maximum score was 14 .

\section{Omeprazole}

Omeprazole was administered to children through an Investigation New Drug exemption. Open-labeled omeprazole was administered before meals either in whole capsule or suspension form, or mixed with apple puree. Children $<10$ years of age received $10 \mathrm{mg}$ twice daily and children $\geq 10$ years received $20 \mathrm{mg}$ twice daily. Omeprazole dosage was increased by $50 \%$ only if upper GI symptoms were still present at the times of re-assessment, to a maximum of $20 \mathrm{mg}$ twice daily for children $<10$ years age and $40 \mathrm{mg}$ twice daily for children $\geq 10$ years.

\section{Statistical Analysis}

Paired Student $t$ tests were used to compare mean peak gastrin with baseline levels and to compare mean peak gastrin before omeprazole treatment versus postomeprazole treatment. Change in symptom scores during treatment were compared using paired Student $t$ tests. Wilcoxon rank-sum tests were used for testing measures of increase in gastric acid production.

One-way repeated measures analysis of variance contrasts were used to identify differences between measures of acid production. Two-group repeated measures analysis of 


\begin{tabular}{|c|c|c|c|c|c|c|c|c|c|}
\hline Patient & $\begin{array}{l}\text { Age } \\
(y)\end{array}$ & $\begin{array}{c}\text { Time since } \\
\text { diagnosis }(y)\end{array}$ & $\begin{array}{c}\text { Mean } \\
\text { leukocyte } \\
\text { cystine since } \\
\text { diagnosis }\end{array}$ & $\mathbf{G F R}^{\dagger}$ & $\begin{array}{c}\text { Cysteamine } \\
\text { dose }^{\ddagger}\end{array}$ & $\begin{array}{c}\text { Omeprazole } \\
\text { dose }^{\S}\end{array}$ & $\begin{array}{c}\text { Baseline } \\
\text { symptom } \\
\text { score }\end{array}$ & $\begin{array}{c}\text { Final } \\
\text { symptom } \\
\text { score }^{q}\end{array}$ & $\begin{array}{c}\text { Weight gain/ } \\
\text { Baseline }^{\#} \\
\text { weight (kg) }\end{array}$ \\
\hline 10 & 2.2 & 1.6 & 1.6 & 139.3 & 58.8 & 4.3 & 8 & 0 & $2.0 / 8.55$ \\
\hline I & 2.7 & 1.5 & 1.8 & 139.7 & 48.9 & 4.0 & 3 & 1 & $0.8 / 9.2$ \\
\hline 3 & 2.8 & 1.0 & 0.9 & 148.6 & 48.0 & 3.1 & 10 & 0 & $0 / 12.5$ \\
\hline 5 & 3.1 & 2.1 & 1.6 & 72.1 & 43.0 & 4.2 & 9 & 2 & $0.3 / 9.3$ \\
\hline 11 & 3.5 & 1.9 & 1.3 & 103.4 & 92.1 & 1.3 & 4 & 0 & $1.4 / 15.2$ \\
\hline 2 & 6.0 & 5.0 & 1.4 & 109.4 & 59.2 & 2.6 & 7 & 1 & $0.4 / 15.2$ \\
\hline 8 & 7.8 & 2.7 & 1.8 & 52.8 & 58.1 & 2.1 & 7 & 0 & $2.0 / 17.2$ \\
\hline 4 & 8.0 & 6.7 & 0.9 & 81.3 & 57.6 & 1.6 & 7 & 2 & I.I/24.2 \\
\hline 6 & 9.6 & 7.3 & 1.2 & 93.8 & 64.2 & 1.8 & 5 & 1 & $0.8 / 21.8$ \\
\hline 9 & 10.7 & 8.1 & 0.7 & 68.3 & 77.7 & 1.2 & 5 & 0 & $2.2 / 30.9$ \\
\hline 7 & 12.3 & 8.9 & 0.8 & 68.5 & 52.3 & 2.6 & 9 & 1 & $0.7 / 30.6$ \\
\hline
\end{tabular}

*Leukocyte cystine levels are measured in nmol half-cystine per mg protein. Normal level is $<0.2$; cystinosis patients have values $>2.0$, and optimal levels with cysteamine therapy should be $<1.0$.

$\dagger$ Glomerular filtration rate $\left(\mathrm{mL} / \mathrm{min} / 1.73 \mathrm{~m}^{2}\right)$ calculated from 0.55 length $(\mathrm{cm}) /$ plasma creatinine $(\mathrm{mg} / \mathrm{dL})^{17}$.

$\ddagger$ Cysteamine $(\mathrm{mg} / \mathrm{kg} / \mathrm{day})$ given in four equal doses and calculated as free-base cysteamine.

$\$ O$ meprazole $(\mathrm{mg} / \mathrm{kg} /$ day $)$ dosage at end of study

\|Symptom score before omeprazole therapy.

१ Symptom score after 16 weeks of omeprazole therapy.

\#Weight gain during the 16 week study period and baseline weight.

\begin{tabular}{lccc}
\hline Table II. Pre- and post-omeprazole serum gastrin data from I I children with cystinosis after cysteamine \\
\hline & $\begin{array}{c}\text { Pre-omeprazole therapy } \\
\text { mean } \pm \text { SEM (range) }\end{array}$ & $\begin{array}{c}\text { Post-omeprazole therapy } \\
\text { mean } \pm \text { SEM (range) }\end{array}$ & P value \\
\hline Mean baseline gastrin & $48.8 \pm 7.1(0-84)$ & $108 \pm 27.1(36-327)$ & .057 \\
Mean gastrin 30 min Post-baseline & $73.9 \pm 10.5(32-128)$ & $187.8 \pm 36.5(51-366)$ & $<.001$ \\
Mean peak gastrin over $2 \mathrm{~h}^{*}$ & $85.9 \pm 12.1(45-177)$ & $217.6 \pm 37.5(55-366)$ & $<.01$ \\
Mean peak gastrin over $2 \mathrm{~h}$ vs mean baseline & 85.9 vs 48.8 & 217.6 vs 108 & $\begin{array}{c}\text { Pre-omeprazole }<.01 \\
\end{array}$ \\
& & & Post-omeprazole $<.01$ \\
\hline
\end{tabular}

Serum gastrin is reported as $\mathrm{pg} / \mathrm{mL}$. Observed significance is provided for different comparisons of serum gastrin.

*Mean of the highest gastrin levels measured within 2 hours post-cysteamine ingestion.

variance was used to test the effects of omeprazole treatment (pre- vs post-) and time and their interaction on gastrin levels. Slices tested treatment effects at individual times. The same analyses were used for gastric acid, with omeprazole treatment (pre- vs post-) and increase in acid production (BAO vs MAO vs $\mathrm{PAO}$ ) as the main effects.

Pairwise tests were two-tailed. No formal adjustments were made to control the overall type I error rate. Instead, unadjusted $P$ values are reported.

\section{RESULTS}

Eleven children, ages 1.7 to 12 years (mean age, 5.7 years, 8 girls and 3 boys), were enrolled into the study from July 2001 to January 2002 (Table I). The mean age at diagnosis was 22 months (1.8 years). None of the children had undergone renal transplantation. Their mean glomerular filtration rate was $97.9 \mathrm{~mL} / \mathrm{min} / 1.73 \mathrm{~m}^{2} .{ }^{17}$ All children had negative Helicobacter pylori serology. Six of the 11 children required nasogastric tube insertion, four had a gastrostomy tube, and one child had a gastrojejunostomy tube in place. The average dose of cysteamine was $59.9 \mathrm{mg} / \mathrm{kg} /$ day and the mean initial leukocyte cystine level was $1.2 \mathrm{nmol}$ half-cystine per milligram. The mean omeprazole dose at the study's start and finish was $1.3 \mathrm{mg} / \mathrm{kg} /$ day and $2.6 \mathrm{mg} / \mathrm{kg} /$ day, respectively. The only adverse effect attributable to omeprazole was mild headaches in one child, but these were not severe enough to discontinue therapy.

\section{Serum Gastrin}

The mean baseline gastrin level increased from 48.8 to $108 \mathrm{pg} / \mathrm{mL}$ while patients received omeprazole (Table II). The highest mean gastrin level occurred 30 minutes after cysteamine ingestion in both cases. The mean peak gastrin levels measured over two hours, before and after omeprazole, were $85.9 \mathrm{pg} / \mathrm{mL}$ and $217.6 \mathrm{pg} / \mathrm{mL}$, respectively, and were significantly higher than their baseline levels $(P<.01$ for both). 


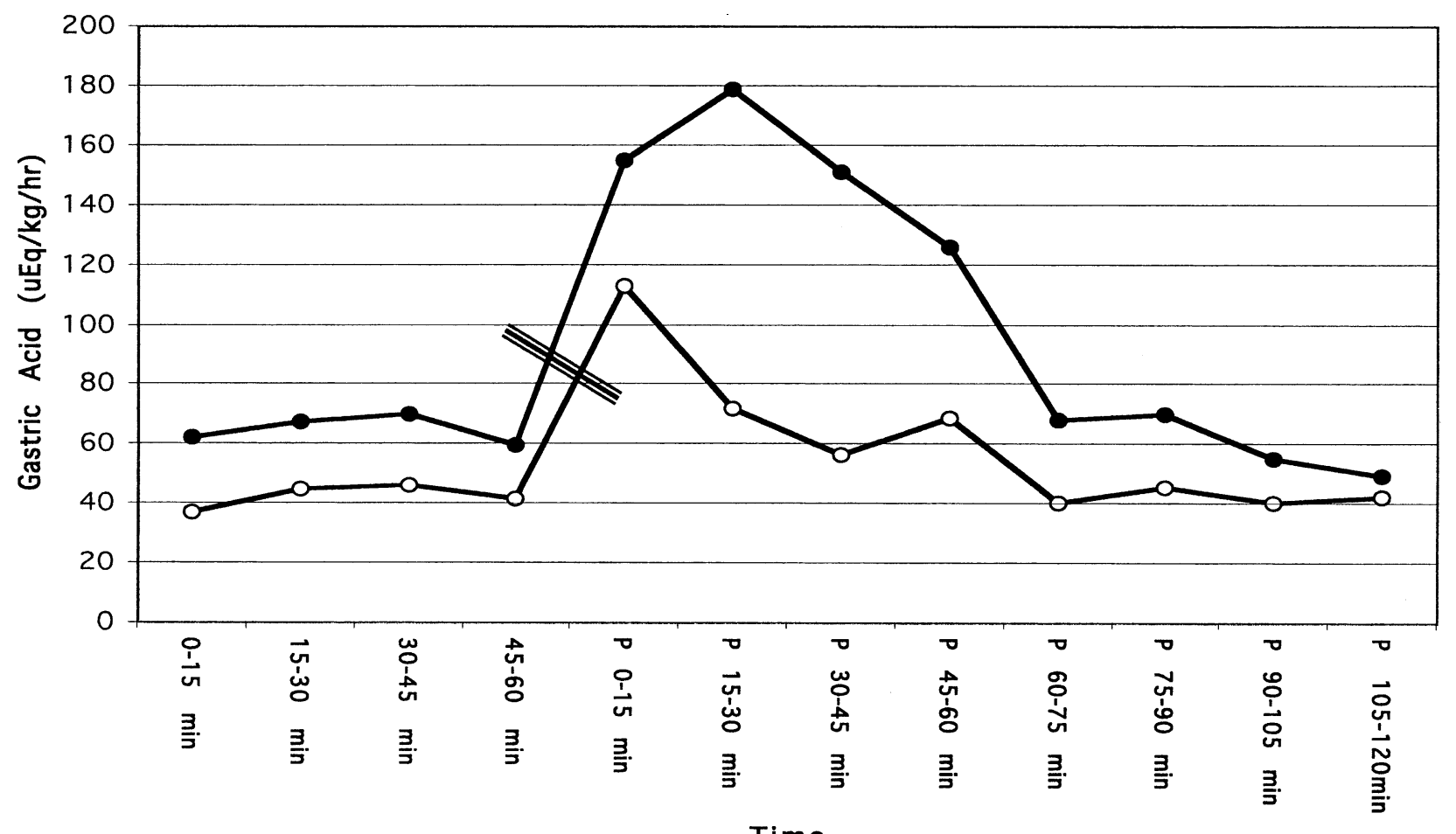

Time

Fig I. Gastric acid secretion in response to cysteamine is shown before (closed circles) and after (open circles) omeprazole therapy, and although collected in 15 -minute periods is reported as $\mu \mathrm{EqH}^{+} / \mathrm{kg} / \mathrm{hr}$. Time 0 to 60 minutes represents the baseline collection of acid. The cysteamine is then ingested and aspirated 30 minutes later (triple diagonal line bar represents the period when gastric aspirate was not collected). Times P 0 to P 120 minutes represent the acid collection after cysteamine is removed from the stomach. The BAO is from 0 to 60 minutes, the MAO is from $\mathrm{P} 0$ to $\mathrm{P} 60$ minutes, and the $\mathrm{PAO}$ in this case is from $\mathrm{P} 0$ to $\mathrm{P} 30$ minutes.

\section{Table III. Pre- and post-omeprazole gastric acid output data for I I children with cystinosis after cysteamine}

\section{Pre-omeprazole therapy \\ mean \pm SEM \\ (range)}

\section{Post-omeprazole therapy mean \pm SEM \\ (range)}

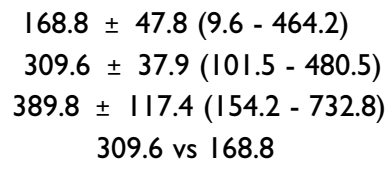

389.8 vs 168.8

\section{$P$ value}

$\begin{array}{lc}\text { Mean BAO } & 256.5 \pm 41.1(82.4-510) \\ \text { Mean MAO } & 611.2 \pm 90.8(155.1-1216.1) \\ \text { Mean PAO } & 728.2 \pm 90.8(284.2-1298.3) \\ \text { Mean MAO vs BAO } & 611.2 \text { vs } 256.5\end{array}$

Mean PAO vs BAO

$$
\begin{gathered}
.34 \\
<.01 \\
<.001
\end{gathered}
$$

Pre-omeprazole $<.01$

Post-omeprazole .05

Pre-omeprazole $<.001$

Post-omeprazole $<.01$

Basal, maximal and peak acid output (BAO, MAO, PAO) are reported in $\mu \mathrm{EqH}+\mathrm{kg} / \mathrm{hr}$. Observed significance is provided for different comparisons of gastric acid secretion.

One child had post-omeprazole serial gastrin levels measured on consecutive days, after intragastric and then intrajejunal cysteamine administration; although baseline levels were similar (150 vs $157 \mathrm{pg} / \mathrm{mL}$ ), the peak gastrin level was almost three times higher after jejunal drug administration (680 vs $278 \mathrm{pg} / \mathrm{mL}$ ).

\section{Gastric Acid Secretion}

Gastric acid production was markedly reduced after omeprazole therapy (Fig 1, Table III). Despite this, cysteamine ingestion resulted in mean $\mathrm{MAO}$ and PAO levels significantly higher than the mean $\mathrm{BAO}$, just as it did before omeprazole therapy. The pre-omeprazole $\mathrm{PAO}$ period in all patients occurred within the first 60 minutes of acid collection postcysteamine, and in seven patients within 30 minutes. The postomeprazole $\mathrm{PAO}$ period occurred within 30 minutes in eight patients.

\section{Upper Gastrointestinal Endoscopy and Biopsy}

Two children had diffuse, fine nodularity throughout the stomach (Fig 2). One child had submucosal hemorrhages in the gastric fundus from recurrent vomiting. Another child 


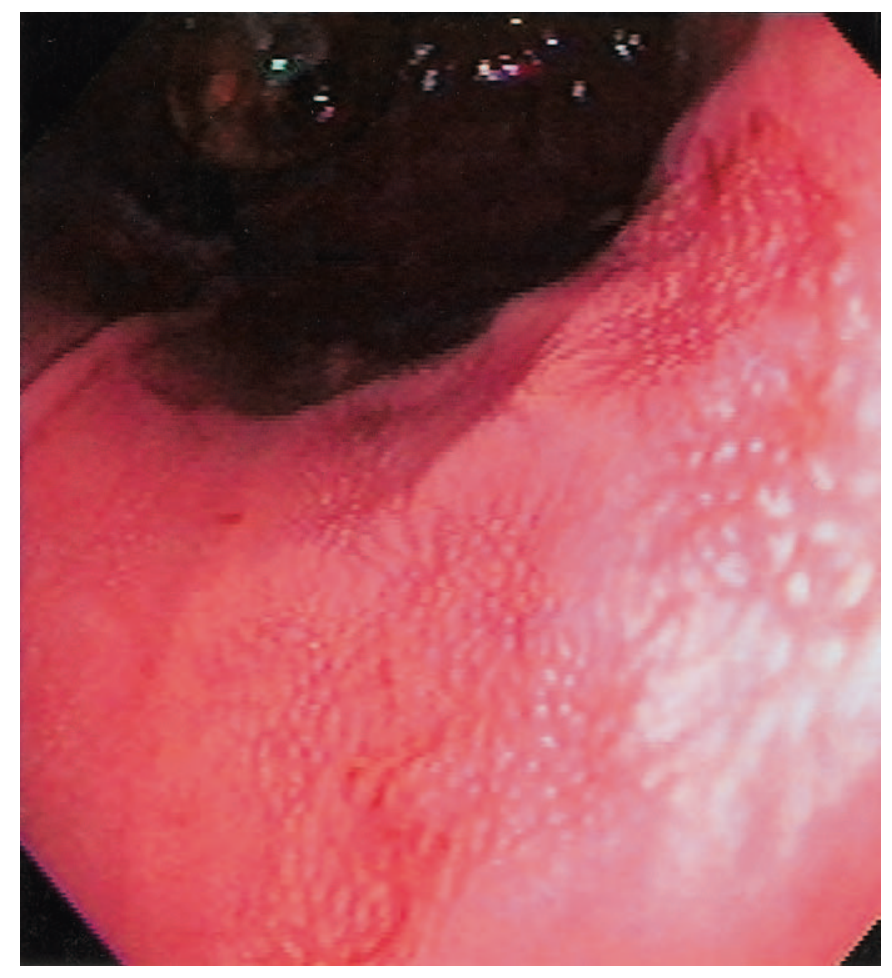

Fig 2. The gastric body as seen through the endoscope. Diffuse, fine nodularity is seen throughout the stomach. Mucosal biopsies did not show Helicobacter pylori infection or evidence of inflammation.

had inspissated bile-stained mucus adherent to the mucosa and a large pool of bile within the stomach. Light microscopy evaluation of biopsy specimens (two per region) from the distal esophagus, gastric body and antrum, duodenal bulb, and jejunum were normal in all except for two patients who had mild esophagitis with basal zone hyperplasia and intraepithelial eosinophils. Helicobacter pylori organisms were not seen. Ten of 11 children, including the four patients with endoscopic abnormalities, had outlines of crystalline structures within the lysosomes of macrophage cells of the lamina propria (Fig 3) presumed to be cystine crystals. Of the 10 patients, one child also had crystals within the jejunal mucosa and one within esophageal mucosa. The two children with the diffusely nodular appearance had the highest levels of crystal deposition with between 18 and 20 crystals per cell.

\section{Symptom Score}

The mean symptom score at the start of the study was 6.9 and fell to $0.7(P<.001)$ after 16 weeks of therapy with omeprazole (Table IV). The patient's symptoms continued to respond to omeprazole therapy at 8 to 12 months after starting treatment. Although they were not part of the symptom score, bloating (before 0.6, after 0.4) and excessive eructation or flatus $(1.2,0.5)$ were also scored before and after treatment with omeprazole.

\section{DISCUSSION}

Oral cysteamine causes duodenal ulcers in laboratory animals. ${ }^{4}$ The dose required, however, is 700 to $1000 \mathrm{mg} / \mathrm{kg}$

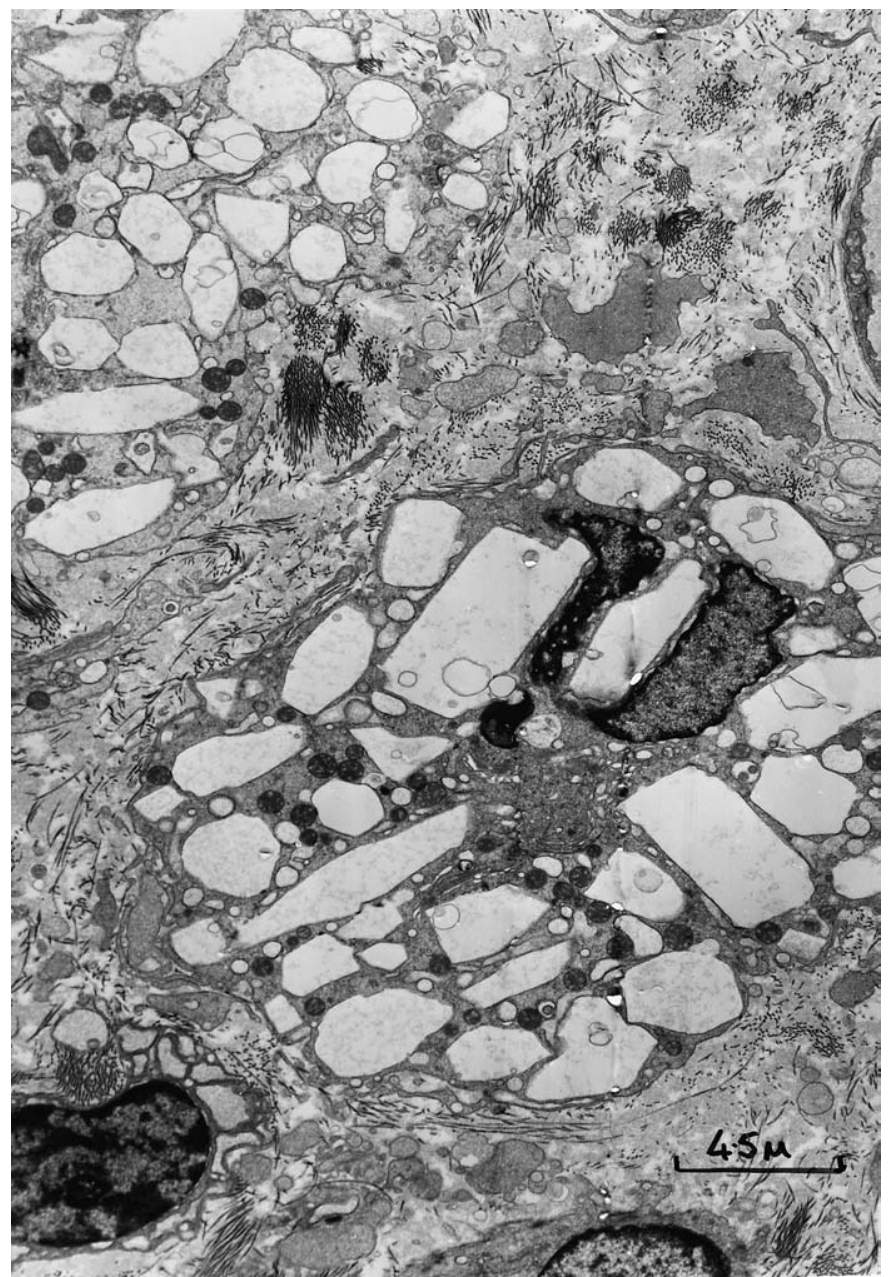

Fig 3. Electron microscopy (original magnification, $\times 9000)$ of the gastric mucosal biopsy reveals several cytoplasmic lysosomal crystalline inclusions of varying shapes and sizes within histiocytes in the lamina propria. The biopsy specimen is fixed in $2.5 \%$ buffered gluteraldehyde, processed for routine electron microscopy and embedded in epoxy resin. Thick sections cut at one micron are stained with toluidine blue and selected areas are stained with uranyl acetate and lead citrate. Ultrathin sections are then examined in an electron microscope.

body weight or 40 to 60 times the per-kilogram body weight dose that is currently administered at any one time for the treatment of cystinosis. ${ }^{1,5-7}$ The exact mechanism by which cysteamine induces ulcerogenesis is unclear, but it likely involves gastric acid-hypersecretion ${ }^{6,18}$ secondary to hypergastrinemia. ${ }^{19}$ Low intraluminal $\mathrm{pH}$ will inhibit gastrin release through a negative feedback loop. High intraluminal $\mathrm{pH}$, as seen in acid-suppression therapy, will cause hypergastrinemia. $^{20}$

In rat studies, a three- to four-fold increase in fasting gastric acid production above baseline was observed after the intraduodenal administration of $100 \mathrm{mg} / \mathrm{kg}$ of cysteamine. ${ }^{18}$ Lichtenberger et al demonstrated a three- to four-fold increase in fasting gastrin levels and a five- to six-fold increase in nonfasting gastrin levels above baseline in rats who received $280 \mathrm{mg} / \mathrm{kg}$ of intragastric cysteamine. ${ }^{19}$ In both sets, the peak gastrin level was at two hours post-ingestion, returned to 
Table IV. Mean symptom score

\begin{tabular}{|c|c|c|c|c|c|c|c|c|}
\hline & Heartburn & Pain & Nausea/Vomiting & Anorexia & Dysphagia & Nocturnal wakening & GI bleed & Total \\
\hline Baseline & 1.0 & 1.4 & 1.8 & 1.7 & 0.6 & 0.3 & 0 & 6.9 \\
\hline 4 week & 0.4 & 0.4 & 0.7 & 0.8 & 0.2 & 0 & 0 & 2.5 \\
\hline 8 week & 0.2 & 0.2 & 0.6 & 0.6 & 0.1 & 0 & 0 & 1.7 \\
\hline 12 week & 0 & 0.3 & 0.3 & 0.4 & 0.1 & 0 & 0 & 1.0 \\
\hline 16 week & 0.2 & 0.1 & 0.2 & 0.3 & 0 & 0 & 0 & 0.7 \\
\hline$P$ value & .01 & $<.001$ & $<.0001$ & $<.0001$ & .025 & .19 & - & $<.0001$ \\
\hline
\end{tabular}

The mean omeprazole dose at start and finish of the study was $1.3 \mathrm{mg} / \mathrm{kg}$ and $2.6 \mathrm{mg} / \mathrm{kg}$, respectively. Statistical analysis of the individual categories was by paired Student $t$ test (baseline vs 16 weeks).

baseline at four hours in the fasting group, but remained elevated for longer in the group that were fed after receiving cysteamine. This postprandial hypergastrinemia in rats may, in part, be the result of the delayed gastric emptying caused by cysteamine, thereby increasing the contact time of food with the gastric mucosa, which may enhance and prolong the release of gastrin. ${ }^{8}$ Other effects of cysteamine that may contribute to ulcer formation include diminished duodenal mucosal blood flow, which is noted within minutes of drug ingestion and may result in the altered production of bicarbonate, mucus and epidermal growth factor from submucosal Brunner's glands. ${ }^{9,21}$

The mean fasting gastrin level was reported as $32.7 \mathrm{pg} /$ $\mathrm{mL}$ in normal control children $<3$ years of age and 14.8 to 20.9 $\mathrm{pg} / \mathrm{mL}$ in children $>3$ years of age. ${ }^{24}$ Our patients had a fasting baseline hypergastrinemia (mean, $48.8 \mathrm{pg} / \mathrm{mL}$ ) that increased and persisted for at least two hours after ingestion of cysteamine (Table II). In two studies of gastric acid secretion in normal children, the mean $\mathrm{BAO}$ was 40 to $67 \mu \mathrm{Eq} / \mathrm{kg} / \mathrm{hr}$, and after pentagastrin $(6 \mu \mathrm{g} / \mathrm{kg})$, there was a five- to eight-fold increase in acid output (MAO versus $\mathrm{BAO}) .{ }^{22,23}$ In the previous study of four cystinosis patients, the mean $\mathrm{BAO}$ was $30 \mu \mathrm{Eq} / \mathrm{kg} / \mathrm{hr}$ and after cysteamine (mean dose, $14.3 \mathrm{mg} / \mathrm{kg}$ ), there was a three-fold increase in acid output (MAO vs BAO).$^{10}$ In our study, the mean BAO was $256.5 \mu \mathrm{Eq} / \mathrm{kg} / \mathrm{hr}$ with similar large increases in MAO and PAO. We cannot explain the discrepancy but it is certainly compatible with our finding of a two- to three-fold increase in baseline gastrin levels compared with normal children. ${ }^{24}$ Further studies to determine how the mode of drug delivery effects gastrin and acid production should be undertaken.

Cysteamine is clearly a potent gastric acid stimulant in humans, even at doses of 11 to $23 \mathrm{mg} / \mathrm{kg}$. Patients in whom baseline acid production was suppressed with omeprazole still demonstrated a mean 1.8-fold increase in maximal acid production above baseline after cysteamine ingestion. The mean peak acid production was demonstrated within 60 minutes of cysteamine ingestion (Fig 1), and this correlated temporally with the onset of GI symptoms in the patients. The mean acid output returned to baseline levels within 90 minutes of cysteamine ingestion. Baseline hypergastrinemia and gastric acid hypersecretion reported here may be have been a residual effect of cysteamine that was ingested eight hours earlier. However, this would seem unlikely because plasma cysteamine concentrations after oral cysteamine bitartrate peak at one to two hours, and gradually fall to immeasurable levels six hours later. $^{25}$

The mean symptom score fell during the study from 6.9 to 0.7 , with the most dramatic improvement occurring within the first four weeks of omeprazole therapy. The most commonly reported symptoms of nausea, vomiting, anorexia, and pain responded best to acid suppression. Most patients required an increase in omeprazole dosage during the study, but had sustained control of symptoms at follow-up 8 to 12 months after the therapy began. This also argues against a nonpharmacological explanation for the decrease in symptom score. We had initially contemplated a placebocontrolled study, but the feasibility study indicated that patient recruitment would be hampered if prolonged or repeated use of the nasogastric tube was required.

The spectrum of GI symptoms in cystinosis patients is wide. ${ }^{11}$ Some patients will have GI symptoms unrelated to cysteamine therapy and these patients may not respond completely to acid-suppression therapy with omeprazole. Although there is some crossover, we believe that the GI symptoms can be broadly categorized into those associated with intestinal dysmotility caused by intralysosomal cystine accumulation, including swallowing dysfunction, gagging, early satiety, and pseudo-obstruction, and those caused by cysteamine-induced gastric acid-hypersecretion such as nausea, vomiting, poor appetite, pain, and heartburn.

Long-term use of omeprazole has been studied in adults and is safe. Enterochromaffin-like cell hyperplasia was reported in more than $50 \%$ of patients who received long-term (mean, 7.9 years) proton-pump inhibitor therapy. This was thought to be a trophic effect of the associated hypergastrinemia. No evidence of dysplasia was reported even after 10 years of therapy. ${ }^{26}$

Lysosomal cystine crystals were identified in gastric mucosa with electron microscopy in 10 patients; the two children with additional esophageal or jejunal involvement had the highest initial symptom scores. The easy identification of these crystals, despite depressed leukocyte cystine levels, suggests that the current recommended cysteamine dosage is either inadequate or not followed. We hope concurrent acid suppression will allow patients to tolerate more aggressive cysteamine therapy, thereby promoting better intra-cellular cystine depletion. We intend to use some of the cystine deposition data as a basis for further studies to establish the 
value of electron microscopy of mucosal tissue as a means of assessing intestinal cystine content and therefore its use in monitoring the effectiveness of cysteamine therapy or drug compliance.

We are indebted to the children and parents who participated in this study; to the nurses at the General Clinical Research Center, UCSD; to Susan Korosy for her organizational skills; to Anne Peters for her electron microscopy work; to Doctors Jon I. Isenberg and Stanley A. Mendoza for reviewing this manuscript and for their instructive comments.

\section{REFERENCES}

1. Gahl WA, Thoene JG, Schneider JA. Cystinosis. N Engl J Med 2002;347:111-21.

2. Gahl WA, Reed GF, Thoene JG, Schulman JD, Rizzo WB, Jonas AJ, et al. Cysteamine therapy for children with nephropathic cystinosis. N Engl J Med 1987;316:971-7.

3. Markello TC, Bernardini IM, Gahl WA. Improved renal function in children with cystinosis treated with cysteamine. N Engl J Med 1993;328: 1157-62.

4. Selye H, Szabo S. Experimental model for production of perforated duodenal ulcers by cysteamine in the rat. Nature 1973;244:458-9.

5. Pfeiffer DC, Pfeiffer CJ, Szabo S. Development of cysteamine-induced ultrastructural surface changes on duodenal mucosa. Lab Invest 1987;56: 444-50.

6. Kirkegaard P, Poulson SS, Loud FB, Halse C, Christiansen J. Cysteamine-induced duodenal ulcer and acid secretion in the rat. Scand J Gastroenterol 1980;15:621-4.

7. Poulson SS, Skov Olsen P, Kirkegaard P. Healing of cysteamine induced ulcers in the rat. Dig Dis Sci 1985;30:161-7.

8. Lichtenberger LM, Szabo S, Reynolds ES. Gastric emptying in the rat is inhibited by duodenal ulcerogens, cysteamine, and propionitrile. Gastroenterology 1977;73:1072-5.

9. Kirkegaard P, Poulsen SS, Halse C, Loud FB, Skov Olsen P, Christansen P. The effect of cysteamine on the Brunner gland secretion in the rat. Scand J Gastroenterol 1981;16:93-6.

10. Wenner WJ, Murphy JL. The effects of cysteamine on the upper gastrointestinal tract of children with cystinosis. Pediatr Nephrol 1997;11: 600-3.
11. Elenberg E, Norling LL, Kleinman RE, Ingelfinger JR. Feeding problems in cystinosis. Pediatr Nephrol 1998;12:365-70.

12. AstraZeneca. Prilosec delayed-release capsules product information, current FDA approved labeling, No. 7910930, issued August 1998.

13. Lindstedt $\mathrm{G}$, Olbe L, Kilander AF, Armbrecht U, Jagenburg R, Runsteen D, et al. Analytical and clinical evaluation of a radioimmunoassay for gastrin. Clin Chem 1985;31:76-82.

14. Isenberg JI, Grossman MI, Maxwell V, Walsh JH. Increased sensitivity to stimulation of acid secretion by pentagastrin in duodenal ulcer. J Clin Invest 1975;55:330-7.

15. Carpenter HA, Talley NJ. Gastroscopy is incomplete without biopsy: clinical relevance of distinguishing gastropathy from gastritis. Gastroenterology 1995;108:917-24.

16. Dohil R, Hassall E, Jevon G, Dimmick J. Gastritis and gastropathy of childhood. J Pediatr Gastroenterol Nutr 1999;29:378-94.

17. Schwartz GJ, Haycock GB, Edelman CM, Spitzer A. A simple estimate of glomerular fitration rate in children derived from body length and plasma creatinine. Pediatrics 1976;58:259-63.

18. Ishii $Y$, Fujii $Y$, Homma M. Gastric acid stimulating action of cysteamine in the rat. Eur J Pharmacol 1976;36:331-6.

19. Lichtenberger LM, Szabo S, Trier JS. Duodenal ulcerogens, cysteamine, and proprionitrile stimulate serum gastrin levels in the rat. Gastroenterology 1977;73:1305-8.

20. Lamberts R, Creutzfeldt W, Struber HG, Brunner G, Solcia E. Longterm omeprazole therapy in peptic ulcer disease: gastrin, endocrine cell growth, and gastritis. Gastroenterology 1993;104:1356-70.

21. Poulsen SS, Kirkegaard P, Skov Olsen P. Christiansen J. Brunner's glands of the rat during cysteamine ulceration. Scand J Gastroenterol 1981;16: 459-64.

22. Lari J, Lister J, Duthie HL. Response to gastrin pentapeptide in children. J Pediatr Surg 1969;3:682-90.

23. Euler AR, Byrne WJ, Campbell LPN. Basal and pentagastrinstimulated gastric acid secretory rates in normal children and in those with peptic ulcer disease. J Pediatr 1983;103:766-8.

24. Janik JS, Akbar AM, Burrington JD, Burge G. Serum gastrin levels in infants and children. Pediatrics 1977;60:60-4.

25. Schneider JA, Clark KF, Greene AA, Reisch JS, Markello TC, Gahl WA, et al. Recent advances in the treatment of cystinosis. J Inherit Metabol Disord 1995;18:387-97.

26. Lamberts R, Brunner G, Solcia E. Effects of very long (up to 10 years) proton pump blockade on human gastric mucosa. Digestion 2001;64: 205-13. 